\title{
Lift and Drag of Non-conventional Wings at Subsonic Speeds and Zero Angle of Attack - An Experimental Investigation
}

\author{
Abdulkareem Shafiq Mahdi Al-Obaidi ${ }^{1, *}$ and Ting Chern $\mathrm{Wei}^{1}$ \\ ${ }^{1}$ School of Engineering, Faculty of Built Environment, Engineering, Technology \& Design, Taylor's \\ University, Subang Jaya, Selangor DE, Malaysia
}

\begin{abstract}
Various non-conventional wing development shows potential in increasing the aerodynamic performance of airplanes. If the nonconventional wing only improves the aerodynamic performance by a small margin, conventional wing is still a better option for airline operators. This provides opportunity to continue research on non-conventional configurations that can greatly saves the fuel consumption. This research was conducted to examine the lift and drag of non-conventional wings at low subsonic speed and low angle of attack. Analytical method based on DATCOM was used to calculate the lift and drag coefficients of nonconventional cranked wing for comparison with experimental results obtained experimentally using Taylor's wind tunnel (TWT). Experimental lift coefficient shows similar values with the analytical results but experimental drag coefficient had an average difference of $44 \%$. The experimental setup and calibration of TWT were verified and further case studies on nonconventional wing model featuring trailing edge notches were carried out. Analysis of the results from case studies shows that generally the effect of varying the number of notches only had significant effect on drag reduction if the notch depth was higher. For flight condition that does not exceed $4^{\circ}$ angle of attack, lower number of notches at higher notch depth had the best aerodynamic performance. On the other hand, for flight condition that requires cruise angle of attack that exceeds $4^{\circ}$, higher number of notches at higher notch depth had the best aerodynamic performance.
\end{abstract}

\section{Introduction}

Airline operators are aware of the high demand for air travelling as the number of passengers increased exponentially over the past two decades. These numbers are expected to further increase in the future, providing two main challenges for airline operators. The first challenge is to lower down operating cost of airplanes in order to increase profit and secondly to uphold the company's corporate social responsibilities in putting effort to reduce air pollutions caused by combustion emission [1]. A viable solution is to improve aerodynamic performance of airplanes with the aim of reducing fuel consumptions which will decrease operating cost and also minimize negative environmental impact caused by

*Corresponding author: abdulkareem.mahdi@taylors.edu.my 
emissions from airplanes. One key component in improving the aerodynamic performance of an airplane is to improve the design of wings because it is the main source of lift force. Referring to Fig. 1, when lift force, $\mathrm{L}$ is greater than the weight, $\mathrm{W}$, the airplane will have more upward force and when drag force, $\mathrm{D}$ is lesser than thrust force, $\mathrm{T}$, the airplane will have lesser resistance moving forward. This indicates that having a better lift to drag ratio can improve the aerodynamic performance because for the same amount of fuel consumption, the airplane can now travel for a longer distance. The potential of applying non-conventional wing design to improve aerodynamic performance of an airplane can be considered as an option for airline operators [1].

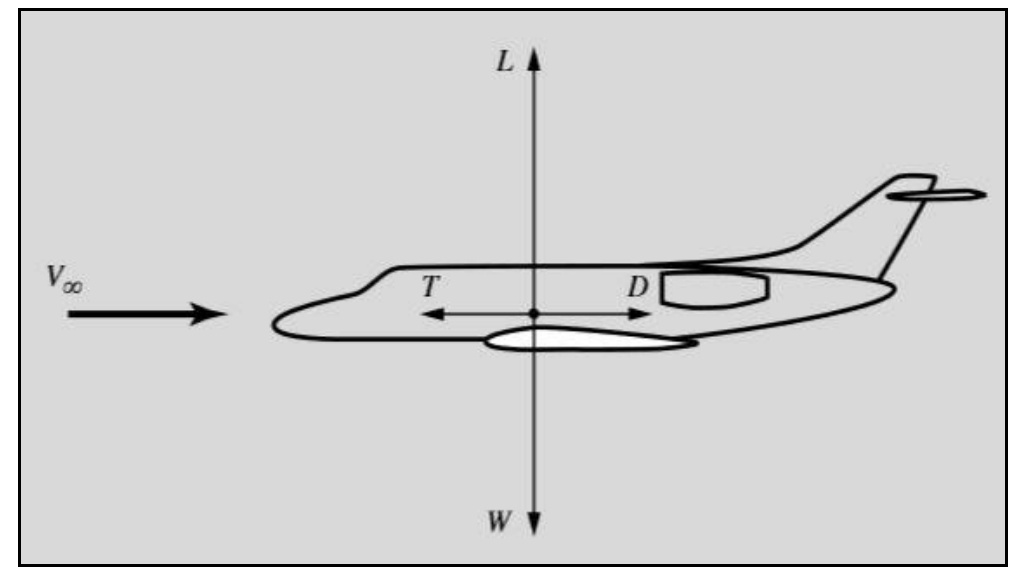

Fig. 1. Forces acting on an airplane [2].

The development of new technologies in the field of non-conventional wings is also part of the NASA's subsonic fixed wing project that aims to improve aerodynamic performance of subsonic transport airplane in the future [3]. Currently, C-wing, blended wing body (BWB) and split wing are the more common non-conventional wing configurations under development. These non-conventional configurations have the same aim of improving aerodynamic performance by reducing fuel consumptions.

Kaushik and Anemaat [4] conducted research on the split wing which has a nonconventional configuration where the left and right wing of the airplane are not aligned. The purpose of this design is to remove the horizontal tail from the low tail which is a common feature on conventional airplanes. Conventional airplanes having horizontal tail experiences downwash from the wings onto the horizontal tail which requires high power control that will leads to additional drag force. If the flaps on the wings are deployed, even more drag force is produced. The removal of horizontal tail on the split wing decreases drag force which will lead to a better fuel consumption. However, in terms of safety aspect, the split wing has asymmetric lift that will results in high tendency for the airplane to roll.

Reist and Zingg [5] studied the blended wing body (BWB) which has a nonconventional configuration of combining the airplane body and wings as one component. This configuration was proven to have high potential in improving aerodynamic performance on larger airplanes. The BWB was designed to have lesser wetted surface area that aims to reduce skin drag friction that contributes to total drag force. Reducing the skin drag friction improves the lift to drag ratio of the BWB. Additional advantage of the BWB is to have a lower operating noise due to the acoustic shielding provided by the aerodynamic design. However, Lyu and Martins [6] stated that the BWB configuration has a challenge in maintaining trim due to uneven pressure distribution over the body and 
wings. Furthermore, the BWB features thick airfoil shape that increases the difficulty in achieving good lift to drag ratio at a reasonable deck angle which is also a concern.

Skinner and Zare-Betash [7] conducted research on the non-conventional C-wing configuration that features a non-planer c-layout that provides high stability and control through the reduction of wing tip vortices. The decrease in wing tip vortices also improves lift to drag ratio through reducing vortex drag. The limitation of the $\mathrm{C}$-wing is the challenge in manufacturing the uncommon wing architecture but this is more minor compared to the disadvantages of the split wing and BWB. Based on the advantages and disadvantages, Cwing is more suitable to be applied on commercial airplanes when compared to split wing and BWB.

The development of non-conventional wings have high potential in improving aerodynamic performance of airplanes but the manufacturing process of non-conventional designs are more complicated which increases the cost of manufacturing. Due to this reason, airline operators will only seriously consider applying non-conventional configuration if the aerodynamic performance can be greatly improved to cover the high manufacturing cost. This provides great opportunity to conduct research and develop new non-conventional configuration that is worth to be considered for application on commercial airplanes. One of nature's creations, the bird wing is good candidate to inspire a novel non-conventional design.

Different bird species have different wing shapes but are all considered as nonconventional configurations. Besides the compositions of the bird wing such as muscles, bones and feathers that are not considered from an aerodynamic point of view, the different wing shapes may have impacted and contributed positively to the aerodynamic performance of bird flight.

Dvorak [8] performs research on the aerodynamics of bird flight which consists of different functional studies from different parts of the wings. A bird wing can be mainly divided into two parts which are the primaries and secondaries. From the studies, lift force is mainly generated from the secondaries that resemble the airfoil shape for the bird. Primaries also contribute by forming tip slots that reduces wing tip vortex that produces induced drag. A bird varies the tail area located just behind the wing to maintain stability and balance. Overall, main studies on the lift can be performed on the secondaries section to act as a fixed wing for airplanes.

This research was conducted to compare the lift and drag of a non-conventional cranked wing by using analytical method from Data Compendium (DATCOM) and also experimental method using Taylor's wind tunnel (TWT). Further studies were performed to determine the lift and drag of non-conventional wings with the effects of notches on the trailing edge. The non-conventional configuration of having notches shape was inspired from the secondaries section of a bird wing which is the main section to generate lift. Most articles available are researching on the application of the flapping mechanism of bird wing and there are limited studies on the effect of shape, especially notches on the trailing edge of bird wing. This provides opportunity to research on the aerodynamic characteristics, lift and drag of fixed wing with different numbers and different sizes of trailing edge notches.

To determine the wing design with better lift to drag ratio, the non-conventional configuration featuring notches will be compared with conventional wing configuration through experimental investigation using TWT. The scope of this experimental investigation is at conditions of low subsonic speeds and low angle of attacks close to zero.

\section{Research Methodology}

This research examines the lift and drag using analytical method and mainly experimental method which is practicing a quantitative study approach. The research methodology 
includes analytical method for cranked wing, three dimension (3D) modelling of test model, low subsonic speed wind tunnel and case studies on trailing edge notches.

\subsection{Analytical method}

Hoak [9] published a document that consists of four volumes with the title of DATCOM. The DATCOM discussed about analytical prediction methods for static aerodynamic coefficients and dynamic derivatives. Analytical methods in DATCOM allow calculation of individual flying component and summed up for the total result of the whole flying body. This research applies DATCOM analytical method which is in fact a semi-empirical approach, to calculate lift and drag of cranked wing at subsonic speeds. Semi-empirical approach consists of calculated values summed up with values obtained from experimental graphs.

\subsubsection{Calculation of lift force for cranked wing}

Based on DATCOM method, the rate of change of lift coefficient with angle of attack for non-conventional cranked wing at subsonic speed can be determined by applying Eq. (1):

$$
C_{L_{\alpha}}=\left(C_{L_{\alpha}}\right)_{\text {pred }} \frac{\left(C_{L_{\alpha}}\right)_{\text {test }}}{\left(C_{L_{\alpha}}\right)_{\text {pred }}}
$$

where $\left(C_{L_{\alpha}}\right)_{\text {pred }}$ is the predicted lift-curve slope of the cranked wing and $\frac{\left(C_{L_{\alpha}}\right)_{\text {test }}}{\left(C_{L_{\alpha}}\right)_{\text {pred }}}$ is the empirical correlation factor of subsonic lift-curve slope for cranked wing. $\frac{\left(C_{L_{\alpha}}\right)_{\text {test }}}{\left(C_{L_{\alpha}}\right)_{\text {pred }}}$ can be obtained from Fig. 4.1.3.2-52 of DATCOM [9] which is presented as a function of aspect ratio and Mach number. $\left(C_{L_{\alpha}}\right)_{\text {pred }}$ can be obtained from Fig. 4.1.3.2-49 of DATCOM [9] which is presented as a function of aspect ratio, surface-roughness height, Mach number parameter and sweepback angles of mid-chord line of exposed wing, where all parameters can be calculated using Eqs. (2) to (4):

$$
\begin{gathered}
\left(\cos \Lambda_{c / 2}\right)_{e f f}=\frac{1}{S_{W}}\left[\left(\cos \Lambda_{c / 2}\right)_{i} S_{i}+\left(\cos \Lambda_{c / 2}\right)_{o} S_{o}\right] \\
c_{l_{a M}}=c_{l_{a}} / \beta \\
k=c_{l_{a M}} /(2 \pi / \beta)
\end{gathered}
$$

where $\left(\cos \Lambda_{c / 2}\right)_{\text {eff }}$ is the effective sweepback angle of mid-chord line of exposed wing, $\left(\cos \Lambda_{c / 2}\right)_{i}$ is the sweepback angles of mid-chord line of wing inboard panels, $\left(\cos \Lambda_{c / 2}\right)_{o}$ is the sweepback angles of mid-chord line of wing outboard panels, $S_{W}$ is the wing area , $S_{i}$ is the total area of inboard panels of wing and $S_{o}$ is the total area of outboard panels of wing, $c_{l_{a M}}$ is the lift-curve slope corrected for compressibility effect, $c_{l_{a}}$ is the section lift-curve slope with angle of attack at constant flap deflection, and $\beta$ is the Mach number parameter and $k$ is the surface-roughness height. 


\subsubsection{Calculation of drag force for cranked wing}

For the case of drag force, the total drag can be divided into $C_{D_{o}}$, zero-lift drag and $C_{D L}$, drag due to lift which can be express as Eq. (5):

$$
C_{D}=C_{D o}+C_{D L}
$$

Zero-lift drag consists of friction drag and form drag which are mainly affected by surface roughness, wetted area and also airfoil shape. Zero-lift drag of non-conventional cranked wing at subsonic speed can be calculated using Eq. (6):

$$
C_{D_{o}}=C_{f}\left[1+L\left(\frac{t}{c}\right)+100\left(\frac{t}{c}\right)^{4}\right] R_{L S} \frac{S_{w e t}}{S_{r e f}}
$$

where $C_{f}$ is the turbulent flat-plate skin friction coefficient that can be obtained from Fig. 4.1.5.1-26 of DATCOM [9] which is presented as a function of Mach number and Reynolds number based on the reference length, $L$ is the airfoil thickness location parameter and is equal to 1.2 for $(t / c)_{\max }$ located at $x_{t} \geq 0.3 c, t / c$ is the average streamwise thickness ratio of the wing, $R_{L S}$ is the lifting-surface correction factor obtained from Fig. 4.1.5.1-28b of DATCOM [9] which is presented as a function of the Mach number and the cosine of the sweep angle of the airfoil maximum thickness line, $\left(\Lambda_{t / 2}\right)_{\max }, S_{\text {wet }}$ is the wetted area of the wing and $S_{\text {ref }}$ is the reference area which is equal to the $S_{\text {wet }}$. Since the cranked wing features inboard and outboard panels, $C_{D o}$ for both panels has to be calculated and summed up for total zero-lift drag.

To calculate drag due to lift of non-conventional cranked wing at subsonic speed, apply Eq. (7):

$$
C_{D L}=\frac{C_{L}^{2}}{\pi A e}+\Delta C_{D L}=\frac{C_{D L}}{C_{L}^{2}} C_{L}^{2}+\Delta C_{D L}
$$

where $C_{L}$ is the wing lift coefficient, $A$ is the aspect ratio, $e$ is the span-efficiency factor over the parabolic-drag region and $\Delta C_{D_{L}}$ is the portion of the drag due to lift resulting from a breakdown in the leading-edge suction at lift coefficients above the parabolic-dragpolar region. An empirical correlation of $\Delta C_{D L}$ as a function of lift coefficient and aspect ratio is available in Fig. 4.1.5.2-54 of DATCOM [9]. Additional equations required are Eqs. (8) to (10):

$$
\begin{gathered}
\frac{C_{D L}}{C_{L}^{2}}=\frac{1}{\pi A e} \\
e=\frac{C_{L_{\alpha}} / A}{R^{\prime}\left(C_{L_{\alpha}} / A\right)+\pi\left(1-R^{\prime}\right)} \\
R^{\prime}=R_{i}\left(n_{B}-d / b\right)+R_{o}\left(1-n_{B}\right)
\end{gathered}
$$

where $R_{i}$ is inboard panel leading-edge-suction parameters, $R_{o}$ is outboard panel leadingedge-suction parameters. $R_{i}$ and $R_{o}$ can be obtained from Fig. 4.1.5.2-53 of DATCOM [9] which is presented as a function of the Reynolds number based on the leading edge angle, Mach number and leading edge radius which is given as 0.00229 of mean chord length. $n_{B}$ 
is the dimensionless distance from plane of symmetry to break span station, $d / b$ is the ratio of maximum body width to wing span, and $e$ is the span-efficiency factor over the parabolic-drag region.

\subsection{Test model}

To compare the experimental results of lift and drag with the calculated lift and drag using DATCOM analytical method, an identical wing model has to be $3 \mathrm{D}$ modelled and manufactured. The wing model is having a non-conventional cranked wing configuration and using the NACA 0012 airfoil.

\subsubsection{D modelling}

The cranked wing was modelled using 3D computer aided design (CAD) software of SolidWorks 2016 version. The method used for 3D model was to import $\mathrm{x}$ and $\mathrm{y}$ coordinates of the NACA 0012, available in Abbott ad Von Doenhoff [10] and generate the airfoil shape using the imported coordinates. These coordinates are in ratio to chord length. Lofted boss function is used to generate solid between each airfoil to form a cranked wing. Figure 2 shows the top view of the cranked wing with dimensions that are same with the dimensions used for the analytical calculation.

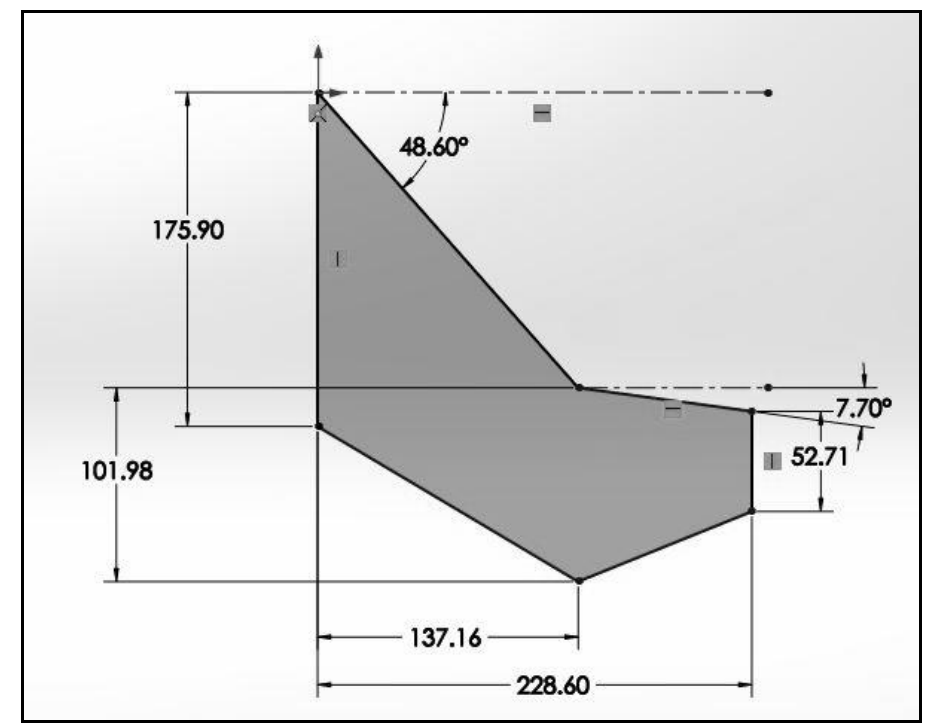

Fig. 2. Dimensions of the cranked wing with units of $\mathrm{mm}$ shown in SolidWorks.

\subsubsection{Manufacturing}

The cranked wing SolidWorks drawing was sent to 3D printer branded as Raise 3D for 3D printing using PolyLactic Acid (PLA) as the printing filament. The print density is set to $100 \%$. Figure 3 shows the 3D printed cranked wing with NACA 0012 airfoil as the test model. 
Fig. 3. 3D printed cranked wing.

\subsection{Low subsonic speed wind tunnel}

The experiments of this research were conducted using a wind tunnel located at Taylor's University, named as Taylor's Wind Tunnel (TWT). Figure 4 shows the TWT that consists of different sections which are the settling camber, contraction section, test section, diffuser and fan. The TWT is an open circuit subsonic wind tunnel model of TDA_M630/12AA/7/28 with a contraction ratio of 3:4:1 [11]. Open circuit wind tunnel, requires air following through an essentially straight path from the entrance to the exhaust section after the fan [12]. The test section of the TWT is rectangular in shape and consists of a square cross section of $0.303 \mathrm{~m} \times 0.303 \mathrm{~m}$ with a length of $0.885 \mathrm{~m}$. The TWT is able to collect force and moment readings through a Gamma DAQ F/T transducer. Readings obtained will be displaced using a PC1 DAQ card model of NI PCI-6220 installed in the computer. The $0.63 \mathrm{~m}$ diameter fan is powered by a 3 horsepower motor with an output torque of $4145 \mathrm{~V} / 50 \mathrm{~Hz}[11]$.

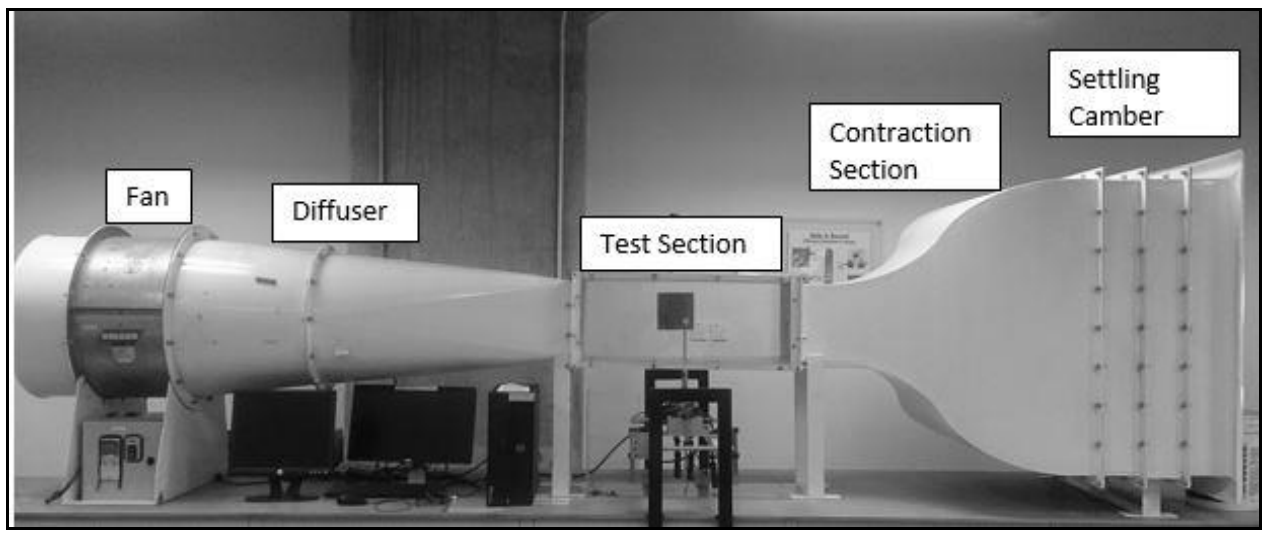

Fig. 4. Taylor's wind tunnel. 
The cranked wing model was mounted on a test rig and placed in the test section as shown in Fig. 5. The location of test rig was mounted $0.1266 \mathrm{~m}$ measured from the leading edge of root chord, which is the aerodynamic centre of the test model. Aerodynamic centre of non-conventional cranked wing can be calculated by using methods presented by Alexander [13].

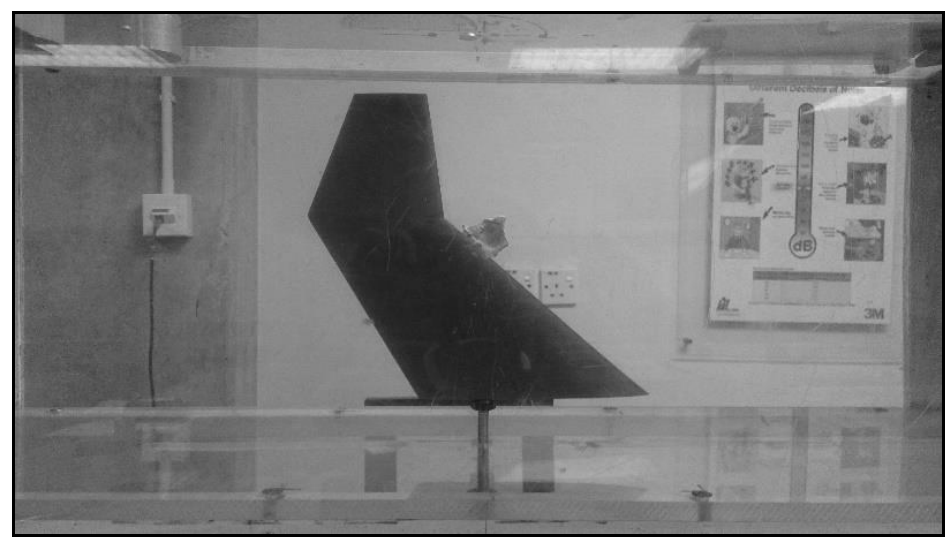

Fig. 5. Test model setup in test section.

The experimental was conducted at Reynolds number, $\mathrm{Re}=1 \times 10^{5}$. To achieve this Reynolds number, the velocity of air flow was calculated to be $11.79 \mathrm{~m} / \mathrm{s}$. The variable that can be vary on the TWT was the frequency of the fan, and the linear equation between frequency and velocity is express as Eq. (11), which was derived from conducting experiment using hot wire and data logger.

$$
f=1.437 V+0.4359
$$

where $f$ is the frequency of the fan and $V$ is the velocity of air.

\subsubsection{Calculating lift coefficient and drag coefficient}

The reading obtained from the TWT computers is lift and drag force instead of lift and drag coefficient which can be calculated using Eqs. (12) and (13):

$$
\begin{gathered}
\text { Lift Force, } L=C_{L} \frac{1}{2} \rho V^{2} S \\
\text { Drag Force, } D=C_{D} \frac{1}{2} \rho V^{2} S
\end{gathered}
$$

where $C_{L}$ is the lift coefficient, $C_{D}$ is the drag coefficient, $\rho$ is the density of air, and $S$ is the wing area. Lift and drag force were obtained by averaging 30 respective force readings from the raw data presented in TWT computer for different angle of attacks. Angle of attack of the test model is adjusted based on a protractor located on top of the test section.

\subsubsection{Effect of test rig on drag coefficient}

One important factor that has to be taken in consideration is the effect of test rig. The test rig that was used to mount the test wing model will affect the readings taken from TWT. 
However the presence of the test rig only affects the drag force and will not affect the lift force due to the shape of the test rig. Since it is a cylindrical rod, it was assume to have symmetrical shape and no difference in angle of attack which will not produce lift force as the air flow passes the test rig. However, the test rig will induce drag by contributing to the friction drag and form drag. Because of that the drag force obtained from TWT is the combination of wing model and test rig while the lift force reading was not affected. To obtain the drag coefficient only for the test model, an equation as shown in Eq. (14) [14] was applied. The effect of test rig was considered in all experiments because it caused large difference in the drag coefficient.

$$
C_{D_{\text {Model }}}=C_{D_{\text {Total }}}-C_{D_{R i g}} \frac{S_{\text {Rig }}}{S_{\text {Model }}}
$$

where $C_{D_{\text {Model }}}$ is the drag coefficient of test wing model, $C_{D_{\text {Total }}}$, is the total drag coefficient, $C_{D_{R i g}}$, is drag coefficient of test rig, $S_{R i g}$, is the area of test rig, and $S_{\text {Model }}$, is the wing area of test model.

\subsection{Case studies on the trailing edge notches}

As mention in the introduction, a new non-conventional wing design can be development through inspiration from nature's creation, the bird wing. However, not all types of bird wings are suitable to be applied on airplanes because most bird species applied flapping flight which requires constant movement of wings and some bird species features wings that are unable to fly. In fact only wings from soaring bird species can have potential to be applied on airplanes. Soaring bird species have the ability to maintain flying without flapping its wing which also saves energy through the reduction of metabolic caused by flapping wing movement [15]. This situation is similar to the fixed wing of airplanes. Besides having good aerodynamic characteristic of high aspect ratio, the shape of soaring bird wing may also contribute to the increase in lift to drag ratio.

This research aims to examine the lift and drag of wing model featuring trailing edge notches. Figure 6 shows the notches from the secondaries of a golden eagle which consists of rounded edge. Notches on the primaries have shaper edge and have the ability to bend upwards to act as a wing tip which reduces size of vortices around the wing tip [16]. Experiment will be conducted only on the rounded edge notches because the main wing section that generates lift for the bird is the secondaries wing which has similar shape to airfoil. Experimental investigation was conducted by determining the lift and drag of a NACA 0012 wing with a chord length of $0.15 \mathrm{~m}$ and a span length of $0.15 \mathrm{~m}$ which gives an aspect ratio of 1 . Keeping the aspect ratio and wing area as constant, add notches on the trailing edge for different case studies as shown in Table 1 to study the effects of trailing edge notches on the lift and drag force. Figure 7 shows the top view and isometric view of the $3 \mathrm{D}$ test model for trailing edge notches.

Table 1. Case studies on trailing edge notches.

\begin{tabular}{|c|c|c|c|c|}
\hline Experiments & $\begin{array}{c}\text { Number of } \\
\text { Notches }\end{array}$ & $\begin{array}{c}\text { Depth of } \\
\text { Notches }(\mathbf{m m})\end{array}$ & $\begin{array}{c}\text { Wing Area } \\
\mathbf{( m m}^{\mathbf{2}} \mathbf{2}\end{array}$ & $\begin{array}{c}\text { Aspect } \\
\text { Ratio }\end{array}$ \\
\hline Case 1 & - & - & 22500 & 1 \\
\hline Case 2 & 3 & $10 \mathrm{~mm}$ & 22500 & 1 \\
\hline Case 3 & 5 & $10 \mathrm{~mm}$ & 22500 & 1 \\
\hline Case 4 & 3 & $15 \mathrm{~mm}$ & 22500 & 1 \\
\hline Case 5 & 5 & $15 \mathrm{~mm}$ & 22500 & 1 \\
\hline
\end{tabular}




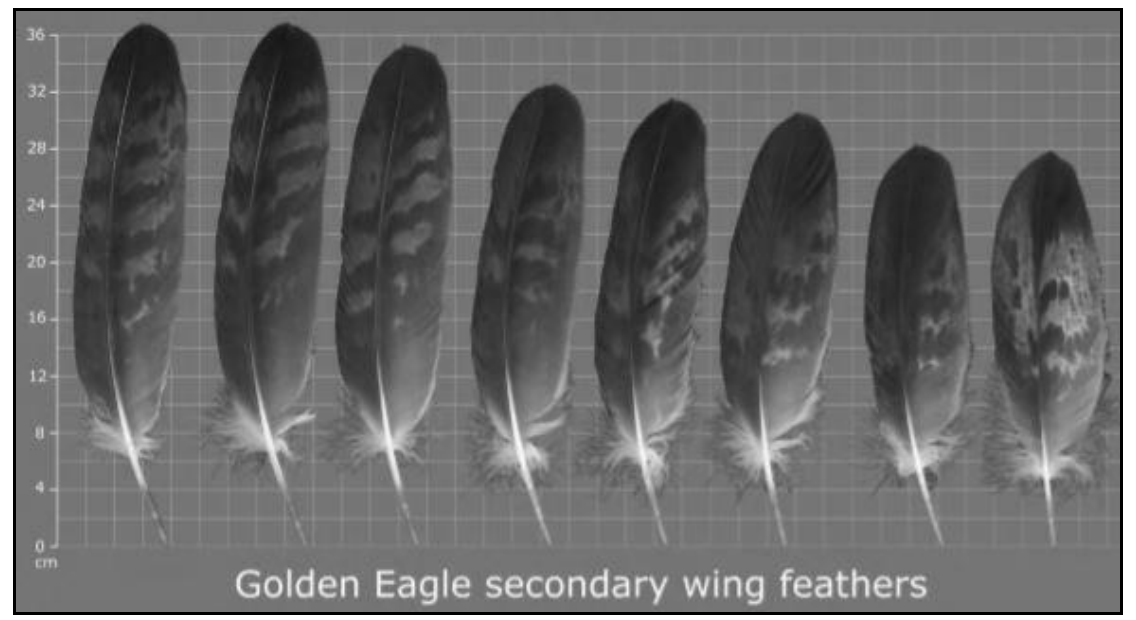

Fig. 6. Rounded edge notches of a golden eagle [17].

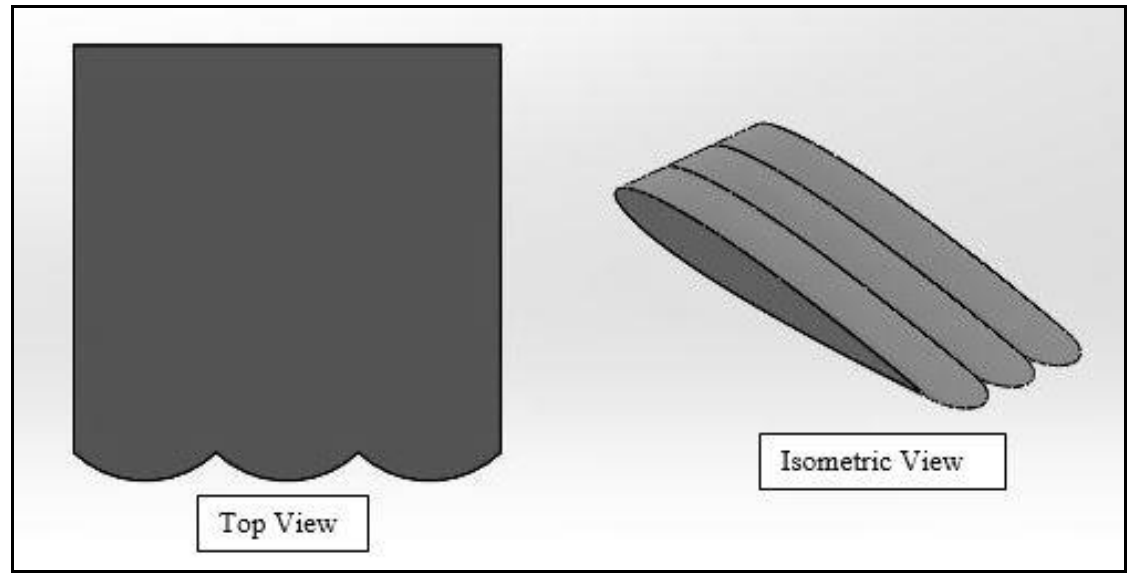

Fig. 7. Top view and isometric view of test model with tailing edge notches in solidworks (not according to scale).

\section{Results and discussion}

Results obtained according to the research methodology will be divided into analytical results and experimental results for more detail discussion. Table 2 shows the list of parameters and values used to perform calculation for both analytical and experimental methods.

\subsection{Analytical results}

Analytical results of the lift coefficient, C_L and drag coefficient, C_D of non-conventional cranked wing was calculated using DATCOM method and the results were plotted in Figs. 8 to 10 . Based on Fig. 8 , the lift coefficient of the test model is directly proportional to the 
angle of attack with a gradient of 0.0605 . At zero angle of attack the lift coefficient is zero because the test model is using NACA 0012, which is a symmetrical airfoil. In the case of drag coefficient, an increase in the angle of attack regardless of positive or negative angle will still result in an increasing value which is shown in Fig. 9. However, unlike lift coefficient, drag coefficient is presence even at zero angle of attack. This is because total drag coefficient is the summation of zero-lift drag, $C_{D o}$ and drag due to lift $C_{D L}$. At zero angle of attack, even there is no drag due to lift, friction drag and form drag are still contributing to the zero-lift drag with the value of 0.011 . For further analyzation, a polar curve as shown in Fig. 10 was plotted, to determine the maximum lift to drag ratio of the test model. The point of maximum lift to drag ratio is actually the tangent line to the C_L vs C_D curve from zero y-intercept. For the non-conventional cranked wing test model, the maximum lift to drag ratio was found to have a value of ten.

Table 2. Parameters and values used for calculation.

\begin{tabular}{|l|c|}
\hline Parameters & Values \\
\hline Mach number, Ma & 0.4 \\
\hline Mach number parameter, $\beta$ & 0.91652 \\
\hline Aspect ratio, $A$ & 4 \\
\hline Wing area, $S_{W}$ & $0.02612 \mathrm{~m}^{2}$ \\
\hline Total area of inboard panels of wing, $S_{i}$ & $0.01906 \mathrm{~m}^{2}$ \\
\hline Total area of outboard panels of wing, $S_{o}$ & $0.00707 \mathrm{~m}^{2}$ \\
\hline Sweepback angles of mid-chord line of wing inboard panels, $\left(\Lambda_{c / 2}\right)_{\mathrm{i}}$ & $40.9^{\circ}$ \\
\hline Sweepback angles of mid-chord line of wing outboard panels, $\left(\Lambda_{c / 2}\right)_{\mathrm{o}}$ & $-7.7^{\circ}$ \\
\hline Section lift-curve slope with angle of attack at constant flap deflection, $c_{l \alpha}$ & $5.7869 \mathrm{per} \mathrm{rad}$ \\
\hline Reynolds number, $R_{l}$ & $5.97 \times 10^{6} \mathrm{per} \mathrm{m}$ \\
\hline Mean chord length of inboard panel, $\bar{C}_{i}$ & $0.14219 \mathrm{~m}$ \\
\hline Mean chord length of outboard panel, $\bar{C}_{o}$ & $0.08001 \mathrm{~m}$ \\
\hline Leading edge angles of wing inboard panels, $\left(\Lambda_{L E}\right)_{\mathrm{i}}$ & $48.6^{\circ}$ \\
\hline Leading edge angles of wing outboard panels, $\left(\Lambda_{L E}\right)_{\mathrm{o}}$ & $7.7^{\circ}$ \\
\hline Aspect ratio of outboard panels, $A_{o}$ & 2.37 \\
\hline Taper ratio of outboard panels, $\lambda_{o}$ & 0.517 \\
\hline Dimensionless distance from plane of symmetry to break span station, $n_{B}$ & 0.6 \\
\hline Ratio of maximum body width to wing span, $d / b$ & 0.139 \\
\hline $\begin{array}{l}\text { Sweep angles of the airfoil maximum thickness line } \\
\text { of wing inboard panels, }\left(\Lambda_{t / 2}\right)_{\max , i}\end{array}$ & $44.2^{\circ}$ \\
\hline $\begin{array}{l}\text { Sweep angles of the airfoil maximum thickness line } \\
\text { of wing outboard panels, }\left(\Lambda_{t / 2}\right)_{\text {max,o }}\end{array}$ & $-2.01^{\circ}$ \\
\hline Wetted area of inboard panels of wing, $\left(S_{W e t}\right)_{\max , i}$ & $0.03812 \mathrm{~m}{ }^{2}$ \\
\hline Wetted area of outboard panels of wing, $\left(S_{W e t}\right)_{\max , o}$ & $0.01414 \mathrm{~m}{ }^{2}$ \\
\hline Average streamwise thickness ratio of the wing, $t / c$ & 0.12 \\
\hline Density of air, $\rho$ & $1.225 \mathrm{~kg} / \mathrm{m}^{3}$ \\
\hline Viscosity of air, $\mu$ & $1.81 \times 10^{-5}$ \\
\hline Mean chord length, $\bar{C}$ & $0.12526 \mathrm{~m}$ \\
\hline Airfoil & $\mathrm{NACA} 0012$ \\
\hline
\end{tabular}




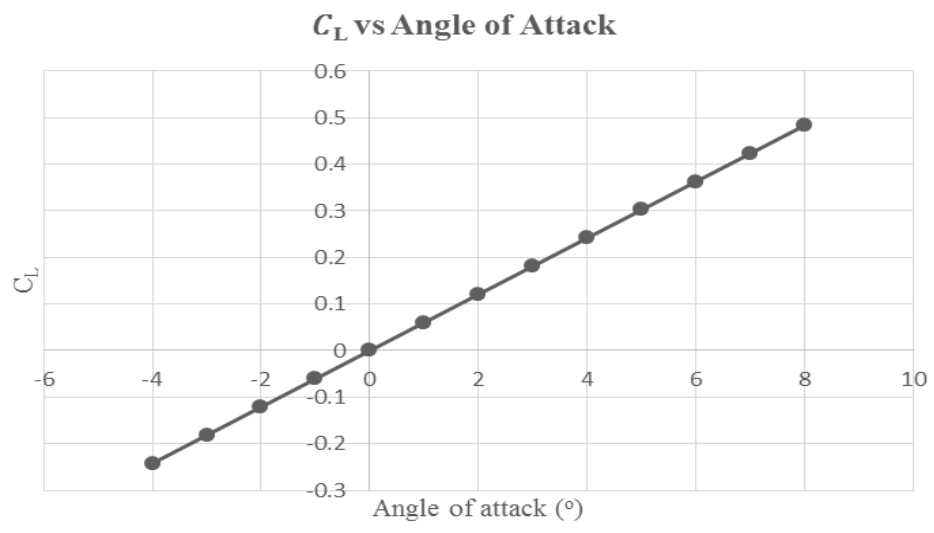

Fig. 8. Lift coefficient against angle of attack.

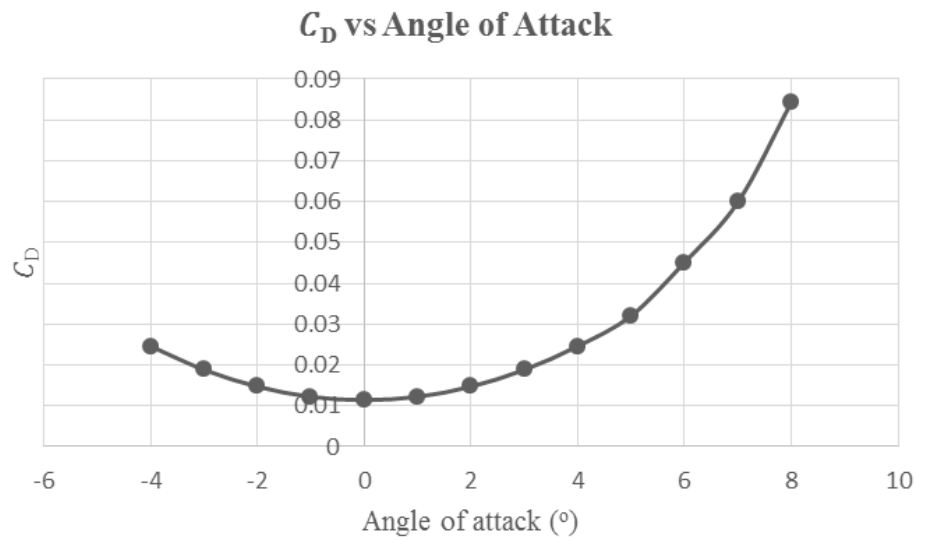

Fig. 9. Drag coefficient against angle of attack.

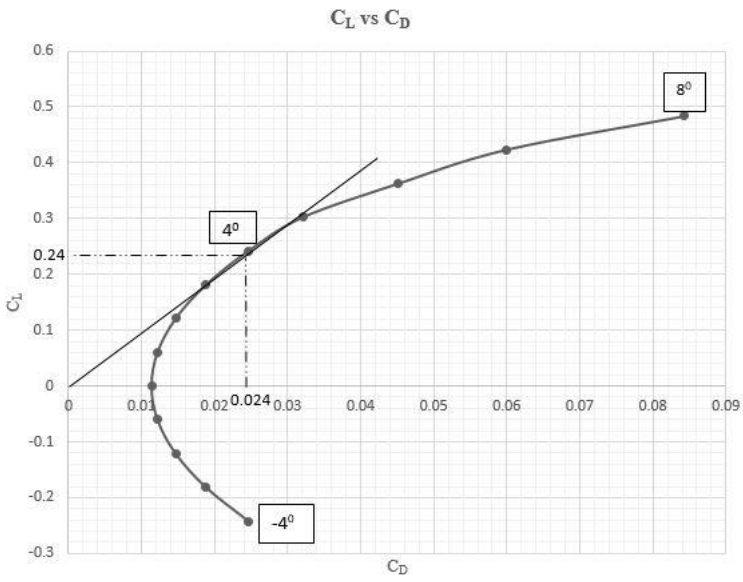

Fig. 10. Polar curve graph of lift coefficient against drag coefficient. 


\subsection{Experimental results}

Experimental data was obtained by using Taylors' wind tunnel and the results were plotted in Figs. 11 and 12 for comparison with the analytical results to verify the experimental setup before conducting experimental investigation on the effect of trailing edge notches. Referring to Fig. 11, the experimental lift coefficient was approximate to be linearly increasing with angle of attack at a gradient of 0.0608 which is very near to the 0.0605 gradient value found using the analytical results. However, as shown in Fig. 12, experimental drag coefficient is not as accurate as experimental lift coefficient. Experimental drag coefficient has an average difference of $44 \%$ when compared to analytical drag coefficient. This error is caused by the drag induced by the test rig holding the test model. The presence of the test rig does not greatly affect the lift coefficient because of its symmetrical shape but it increases the friction drag and form drag that contributes to the total drag force. Because of that, the experimental drag coefficient curve is located higher than the analytical drag coefficient curve but still showing similar curve trend. An experiment was conducted to determine the drag force induced by the test rig and by applying Eq. (14), the drag coefficient for only the test model was calculated. Figure 13 indicates that after subtracting the drag coefficient caused by test rig, the accuracy of experimental results had improved greatly. Based on the comparison, it is found that TWT gives accurate drag coefficient results but less precise than lift coefficient which are both accurate and precise.

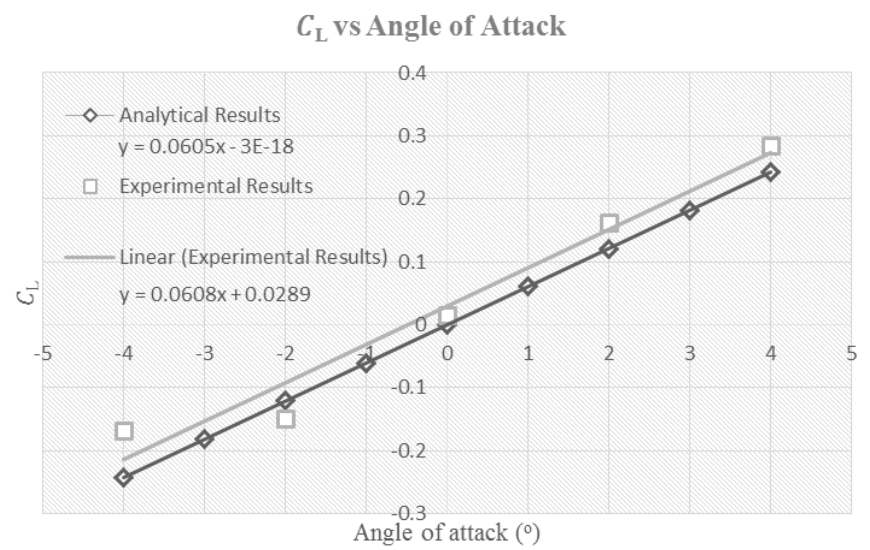

Fig. 11. Lift coefficient against angle of attack.

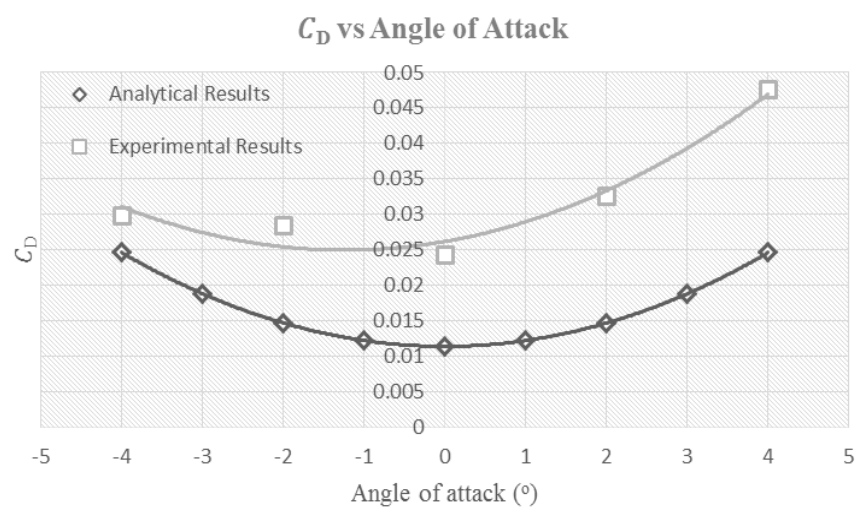

Fig. 12. Drag coefficient against angle of attack. 


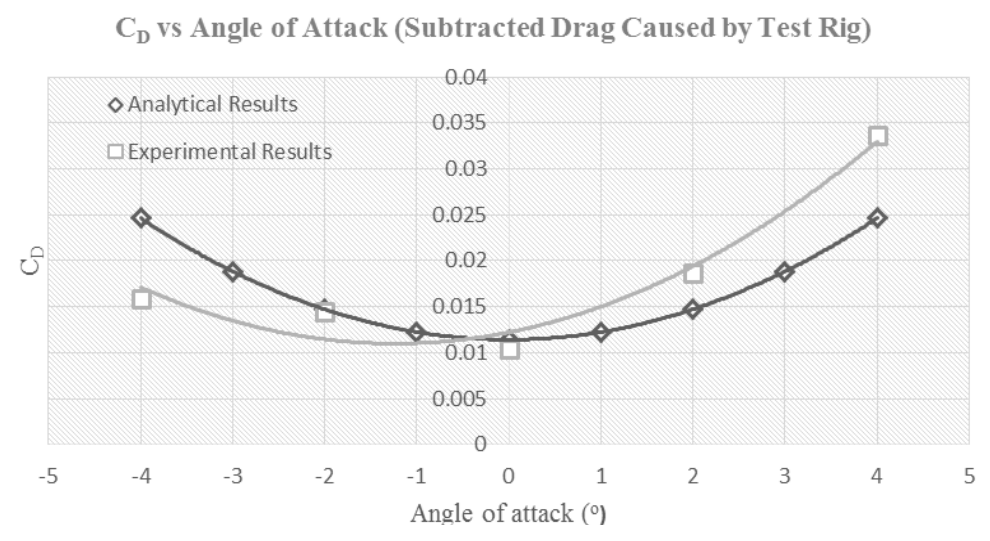

Fig. 13. Drag coefficient (only wing model) against angle of attack.

The experimental setup was verified and further experiments was carried out to study the effects on lift and drag of non-conventional test wing models featuring trailing edge notches and comparing the results with conventional wing model with the same wing area and aspect ratio. Based on the experimental results, it was found that lift force was not greatly affected because all wing models are having the same wing area. However, applying notch shape on the trailing edge may have reduced the vortices at the wake area behind the trailing edge which may result in reduction of drag force. Further analysis from case studies shows that at notch depth of $10 \mathrm{~mm}$, there was no significant reduction in terms of drag even by varying the number of notches from three notches to five notches. However the effect of drag reduction can be clearly seen when the notch depth was increases to $15 \mathrm{~mm}$. With comparison to conventional wing model, non-conventional wing model featuring three notches with $15 \mathrm{~mm}$ notch depth was chosen as the best model for flight condition that does not exceed $4^{\circ}$ angle of attack while non-conventional wing model featuring five notches with $15 \mathrm{~mm}$ notch depth was the better option for flight condition that will exceed $4^{\circ}$ angle of attack.

\section{Conclusions}

To examine the lift and drag of non-conventional wings at low subsonic speed and low angle of attack, analytical and experimental approach was practiced. By using DATCOM analytical method, the lift and drag coefficient of a cranked wing was calculated and plotted in graphs as a function of angle of attack. When compared with experimental results, it was found that the lift and drag obtained from TWT are accurate, provided that the effect of the extra drag caused by the test rig is subtracted. The experimental setup was verify using the comparison results from cranked wing model before conducting further case studies on the non-conventional wing model featuring various trailing edge notches. By analysing the experimental results, it can be concluded that the effects of varying the number of notches only had significant effect on drag reduction if the notch depth is higher. For flight condition that does not exceed $4^{\circ}$ angle of attack, lower number of notches at higher notch depth has the best aerodynamic performance, while higher number of notches at higher notch depth has better aerodynamic performance for flight condition that requires cruising angle of attack that exceed $4^{\circ}$ angle. 


\section{List of Abbreviations}

$\begin{array}{ll}\text { TWT } & \text { Taylor's Wind Tunnel } \\ \text { BWB } & \text { Blended Wing Body } \\ \text { DATCOM } & \text { Data Compendium } \\ \text { 3D } & \text { Three Dimension } \\ \text { NACA } & \text { National Advisory Committee for Aeronautics }\end{array}$

\section{References}

1. Z.W. Teo, T.H. New, B. Nagel, V. Gollnick, AIAA SciTech Forum Expo., 1, pp. 1-10 (2016)

2. J.D. Anderson, Fundamentals of aerodynamics, (McGraw-Hill Education, 2010)

3. B.K. Stanford, C.V. Jutte, C.D. Wieseman, AIAA J., 54(1) pp. 293-309 (2016)

4. B. Kaushik, W. Anemaat, $28^{\text {th }}$ Int. Congr. Aeronaut. Sci., pp. 1-13 (2012)

5. T.A. Reist, D.W. Zingg, AIAA, 1, pp. 1-13 (2014)

6. P.Z. Lyu, J.R.R.A. Martins, J. Aircr., pp. 1-129 (2014)

7. S. Skinner, H. Zare-Betash, 2015 Aerospace Symposium - Aerospace Ecosystem. p. 1 (2015)

8. R. Dvorak, Exp. Fluid Mech. 114, pp. 1-8 (2016)

9. D.E. Hoak, USAF Stability and Control DATCOM, (Flight Control Div. Air Force Flight Dyn. Lab. Rept. 0410, 1972)

10. I.H. Abbott, A.E. Von Doenhoff, Theory of wing sections: including a summary of airfoil data $\left(2^{\text {nd }}\right.$ Ed. New York: Dover Publication, 1959)

11. A.S.M. Al-Obaidi, S. Eftekhari, $3^{\text {rd }}$ eureca conference, Dec 2014 Taylor's University, (2014)

12. A.P. Jewel, B. Barlow, W.H. Rae, Low-speed wind tunnel testing (3rd Ed. WileyInterscience, 1999)

13. M.G. Alexander, Subsonic Wind Tunnel Testing Handbook, 5, pp. 1-291 (1991)

14. A.S.M. Al-Obaidi, H. Wibowo, $8^{\text {th }}$ eureca conference, July 2017, Taylor's University (2017)

15. J. M. Mallon, K.L. Bildstein, T.E. Katzner, Auk, 133(1) pp. 1-8 (2016)

16. M.A. Aldheeb, W. Asrar, E. Sulaeman, A.A. Omar, J. Aerosp. Technol. Manag. 8(1) pp. 7-17 (2016)

17. P.W. Trail, Identification guides for wildlife law enforcement No. 15 pp. 1-26 (2014) 